Supporting information for

\title{
Variability of ammonia and methane emissions from animal feeding operations in northeastern Colorado
}

Levi M. Golston, ${ }^{1, \mathrm{a}}$ Da Pan, ${ }^{1}$ Kang Sun, ${ }^{1, \mathrm{~b}}$ Lei Tao, ${ }^{1}$ Mark A. Zondlo, ${ }^{1, *}$ Scott J. Eilerman, ${ }^{2,3, \mathrm{c}}$ Jeff Peischl, ${ }^{2,3}$ J. Andrew Neuman, ${ }^{2,3}$ and Cody Floerchinger, ${ }^{4, d}$

${ }^{1}$ Department of Civil and Environmental Engineering, Princeton University, Princeton, New Jersey 08544, United States.

${ }^{2}$ Cooperative Institute for Research in Environmental Sciences (CIRES), University of Colorado, Boulder, Colorado 80309, United States.

${ }^{3}$ NOAA Earth System Research Laboratory (ESRL) Chemical Sciences Division, Boulder, Colorado 80305, United States.

${ }^{4}$ Aerodyne Research Inc., Billerica, Massachusetts 01821, United States.

${ }^{a}$ Now at Atmospheric Science Branch, NASA Ames Research Center, Mountain View, California 94043, United States.

${ }^{\mathrm{b}}$ Now at Department of Civil, Structural and Environmental Engineering and RENEW Institute, University at Buffalo, Buffalo, New York 14260, United States.

c Now at Jupiter Intelligence, Boulder, Colorado 80302, United States.

d Now at Harvard's Solar Geoengineering Research Program, Cambridge, Massachusetts 02138, United States.

*Correspondence to: mzondlo@princeton.edu

The supporting information contains the following sections:

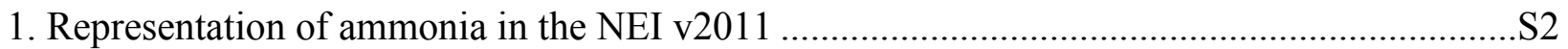

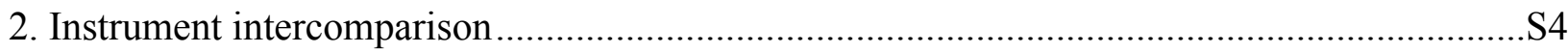

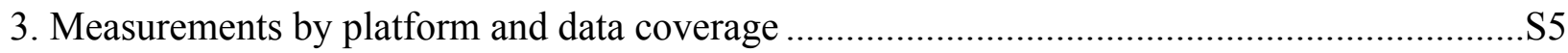

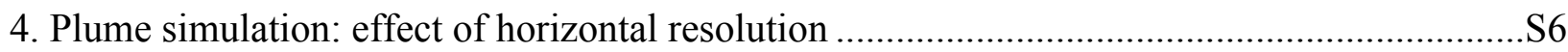

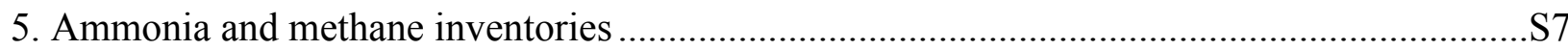

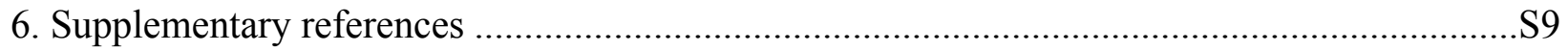




\section{Representation of ammonia in the NEI v2011}

a) NEI beef feedlot process model

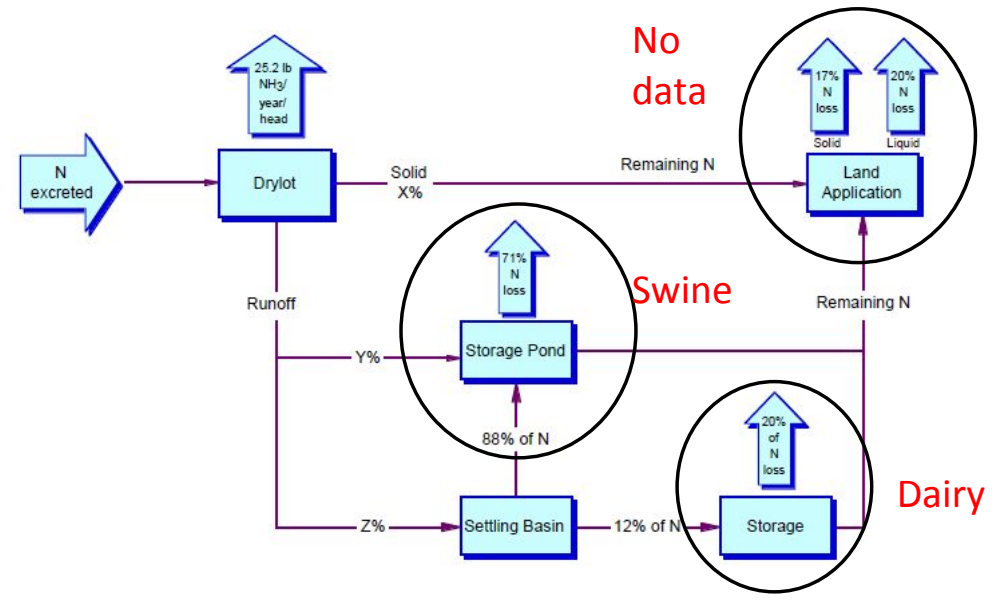

The percentage of nitrogen lost is calculated based on the amount of nitrogen managed in that component.

The amount of nitrogen leaving the settling basin is based on the amount of nitrogen managed in the settling basin.

$\mathrm{X} \%, \mathrm{Y} \%$ and $\mathrm{Z} \%$ vary by size of operation and represent the proportion of operations using each type of system.

b) NEI drylot emission factor

\begin{tabular}{|c|c|c|c|}
\hline & Reference & Original emission factor (EF) & $\begin{array}{c}\text { Converted EF } \\
\text { (lb NH } 3 / y r / h e a d)\end{array}$ \\
\hline & Grelinger, 1997 & $35-50 \mathrm{lb} / \mathrm{day} / 1000$ head & 15.5 \\
\hline & $\begin{array}{l}\text { Hutchtinson et al., } \\
1982\end{array}$ & $0.76-2.82 \mathrm{~g} \mathrm{~N} /$ head/hour & 42.0 \\
\hline & USDA, 2000 & $18 \mathrm{lb} /$ head/year & 18.0 \\
\hline CARB (1999) & \multicolumn{2}{|l|}{ AVERAGE } & 25.2 \\
\hline
\end{tabular}

Figure S1. NEI's beef feedlot manure management train (a) Source: Appendix B, Figure 17 ('Beef - Feedlot') and (b) Source: Table D-15 ('Ammonia Emission Factor for Cattle Drylots'). 
a) Five different MMTs depending on housing

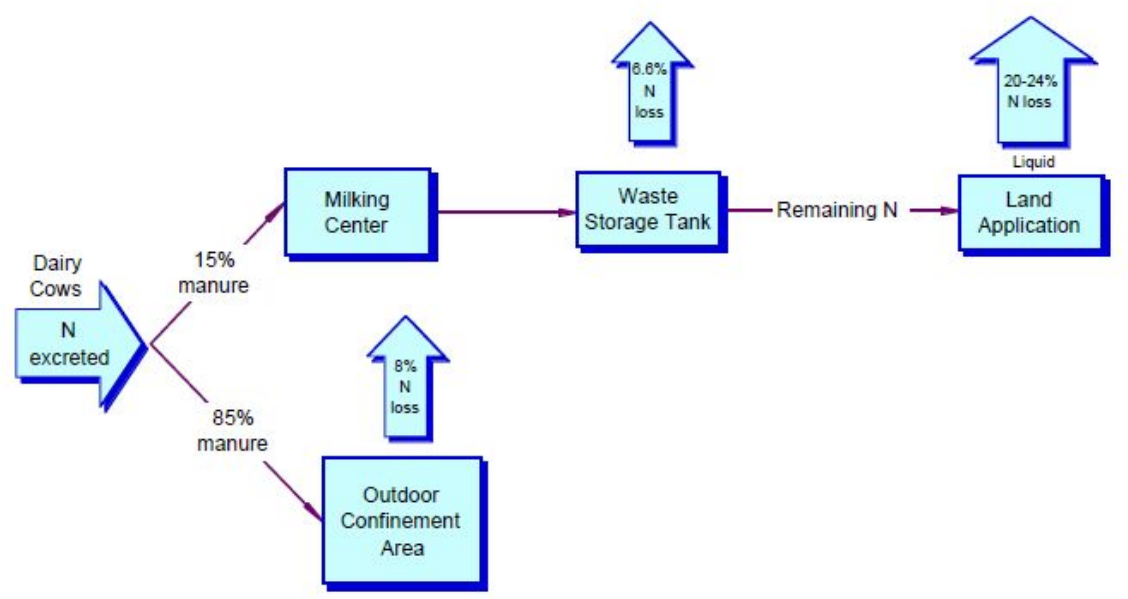

b) Outdoor confinement based on a single study:

\begin{tabular}{|c|l|l|}
\hline Reference & \multicolumn{1}{|c|}{$\begin{array}{c}\text { Original emission } \\
\text { factor (EF) }\end{array}$} & \multicolumn{1}{c|}{ Converted EF } \\
\hline Bouwman et al., 1997 & $8 \%$ of $\mathrm{N}$ & $8 \%$ of $\mathrm{N}$ \\
\hline
\end{tabular}

Other assumptions undocumented

Figure S2. NEI's dairy manure management train (a) Source: Appendix B, Figure 11 ('Dairy Outdoor Confinement Area') and (b) Source: Table D-16 ('Ammonia Emission Factor for Beef and Heifers on Outdoor Confinement Areas'). 


\section{Instrument intercomparison}
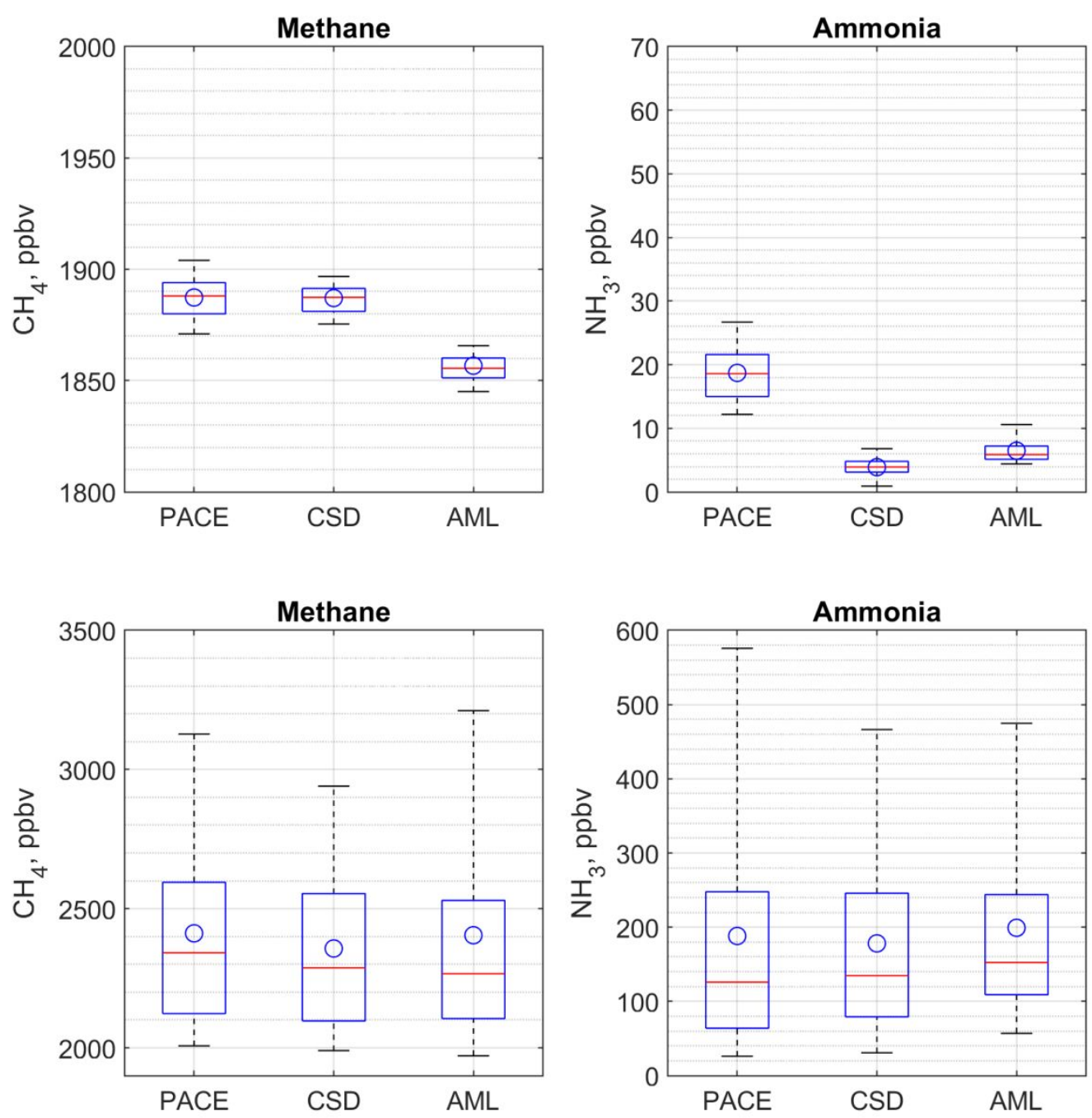

Figure S3. Intercomparison of $\mathrm{CH}_{4}$ and $\mathrm{NH}_{3}$ instruments while the mobile laboratories were collocated (top: at a parking lot, bottom: downwind of a dairy). Boxplots show the 5th, 25th, 50th, 75th, and 95th percentiles and circles the mean values. 


\section{Measurements by platform and data coverage}

Table 1. Data coverage by mobile laboratory (filled boxes mean measurements occurred on that corresponding day).
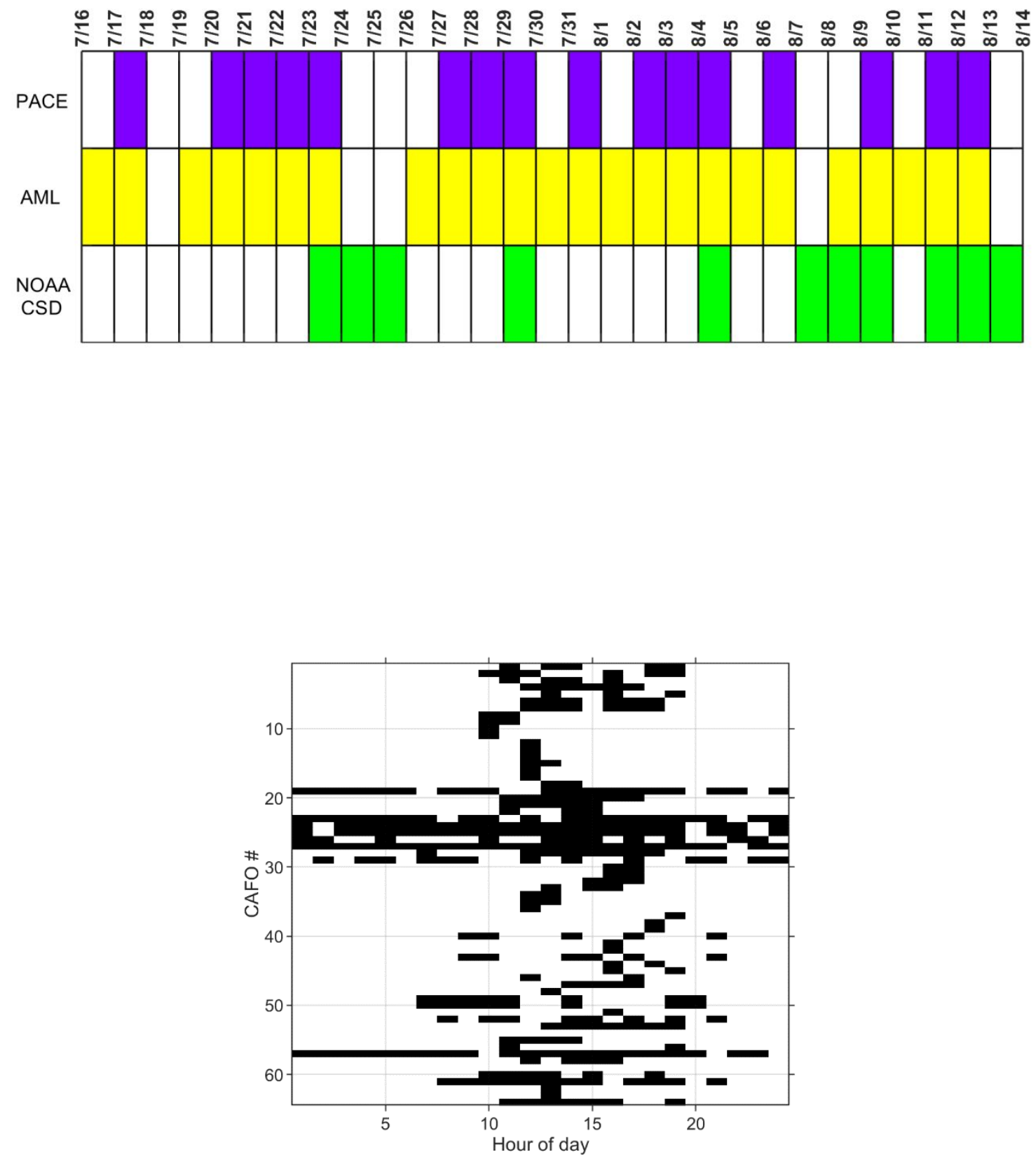

Figure S4. Data coverage binned by time of day, with one-hour bins. Note that CAFO \# is arbitrarily assigned and corresponds to individual sites. 


\section{Plume simulation: effect of horizontal resolution}

A test simulation was conducted comparing a synthetic inverse Gaussian area plume simulation at high source area resolution ( $1 \mathrm{~m}$, regarded as the true value), compared to lower resolution simulations. In all cases, there are the same number of observation points (50) along the roadway. The test case shown is for neutral stability, with a $300 \mathrm{~m}$ by $500 \mathrm{~m}$ rectangular source area, and wind direction offset from perpendicular. With the roadway $100 \mathrm{~m}$ to the east, the 100 m simulation was $15 \%$ too high, while the $50 \mathrm{~m}$ simulation was too high by $5 \%$; the plume shape itself is seen to deviate by a much larger extent especially at $100 \mathrm{~m}$ than these emission estimates. At one CAFO, we drove directly between the feeding pens, so a test simulation is also shown where the roadway cuts through the simulated area source. Here the $50 \mathrm{~m}$ case was too high by $17 \%$, and the $100 \mathrm{~m}$ case too low by $13 \%$.
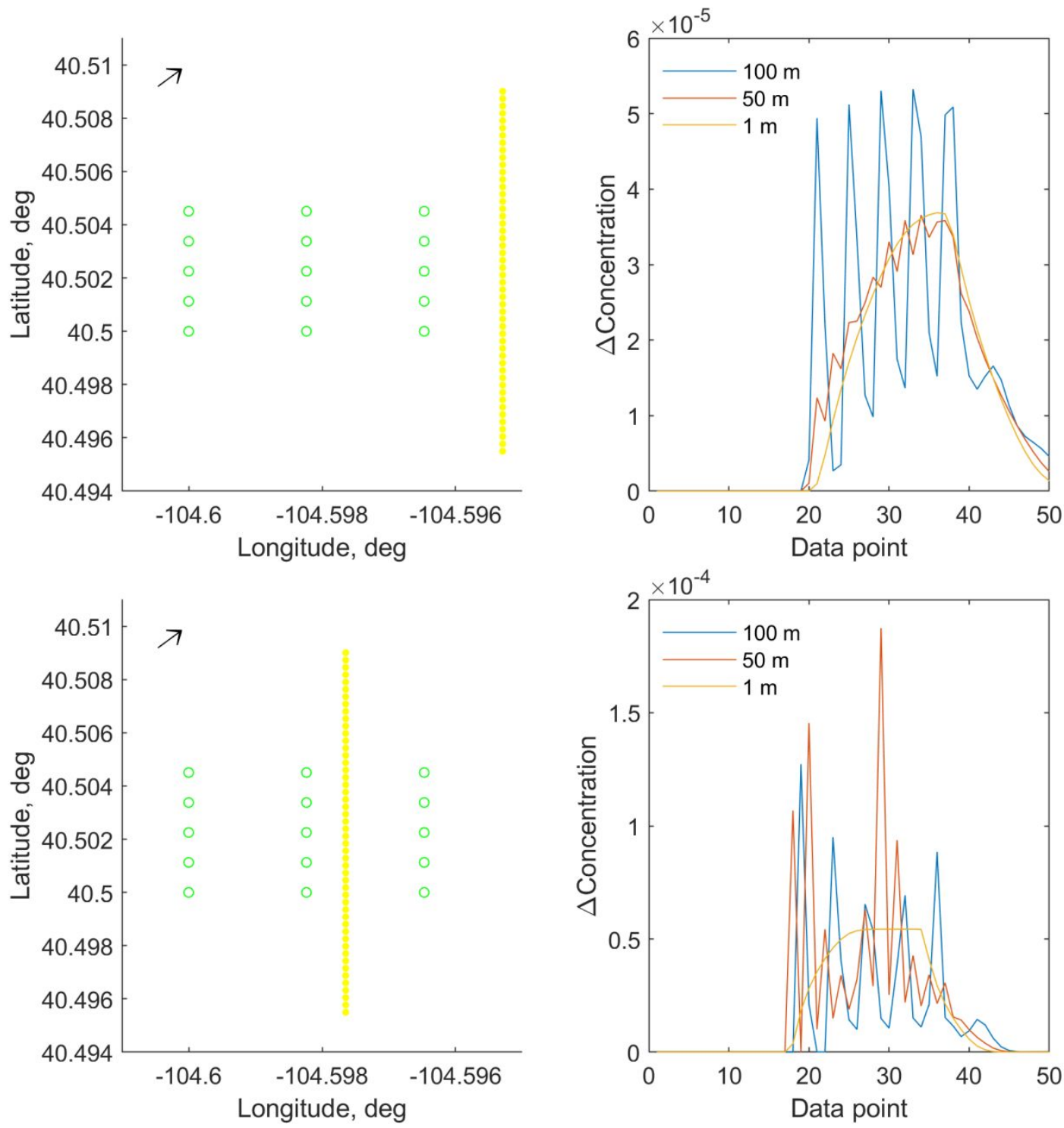

Figure S5. Comparison of simulations at three horizontal resolutions for (top) a roadway $100 \mathrm{~m}$ east of an area source and for (bottom) a roadway within the middle of the area source. Black 
arrow represents the wind direction, yellow circles the observation points on-road, and green circles the discretized area source at $100 \mathrm{~m}$ resolution. 


\section{Ammonia and methane inventories}

a)

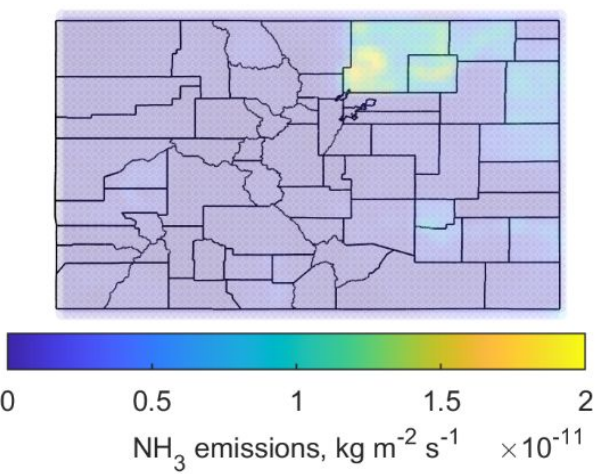

c)

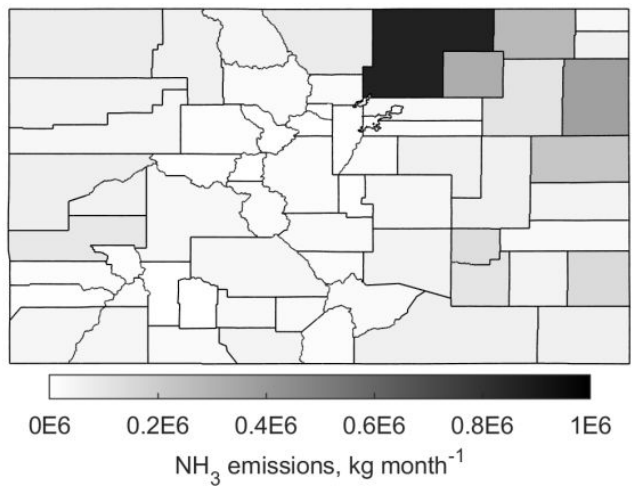

b)

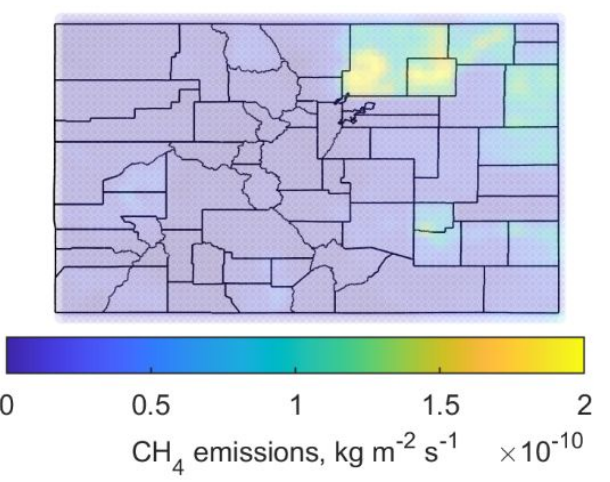

d)

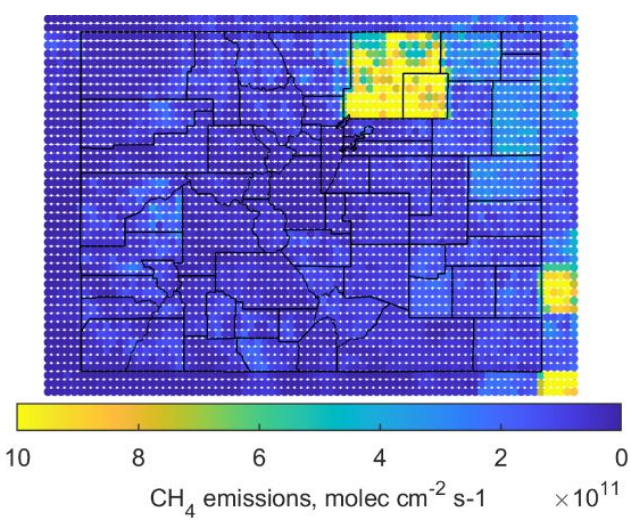

Figure S6. Colorado inventory maps (for the month of August), for

a) $\mathrm{NH}_{3}$ in EDGAR v4.3.2 (year 2010): manure management (4B)

b) $\mathrm{CH}_{4}$ in EDGAR v4.3.2 (year 2010): enteric fermentation (4A) + manure management (4B)

c) $\mathrm{NH}_{3}$ in U.S. NEI 2014v2 (year 2014): livestock waste for cattle and sheep

d) $\mathrm{CH}_{4}$ in U.S. GHGI in Maasakkers et. al. 2016 (year 2012): enteric fermentation (4A) + manure management (4B).

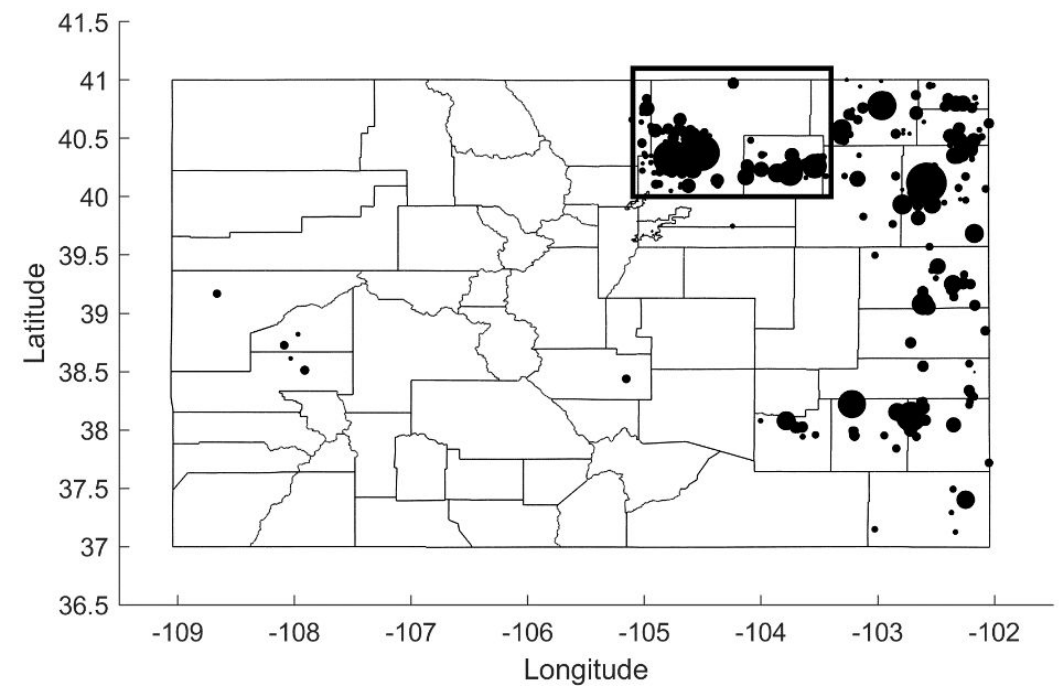


Figure S7. Area integrated for the gridded inventories (EDGAR, US. GHGI). CAFOs in Colorado are shown as filled circles scaled by permitted animal count.
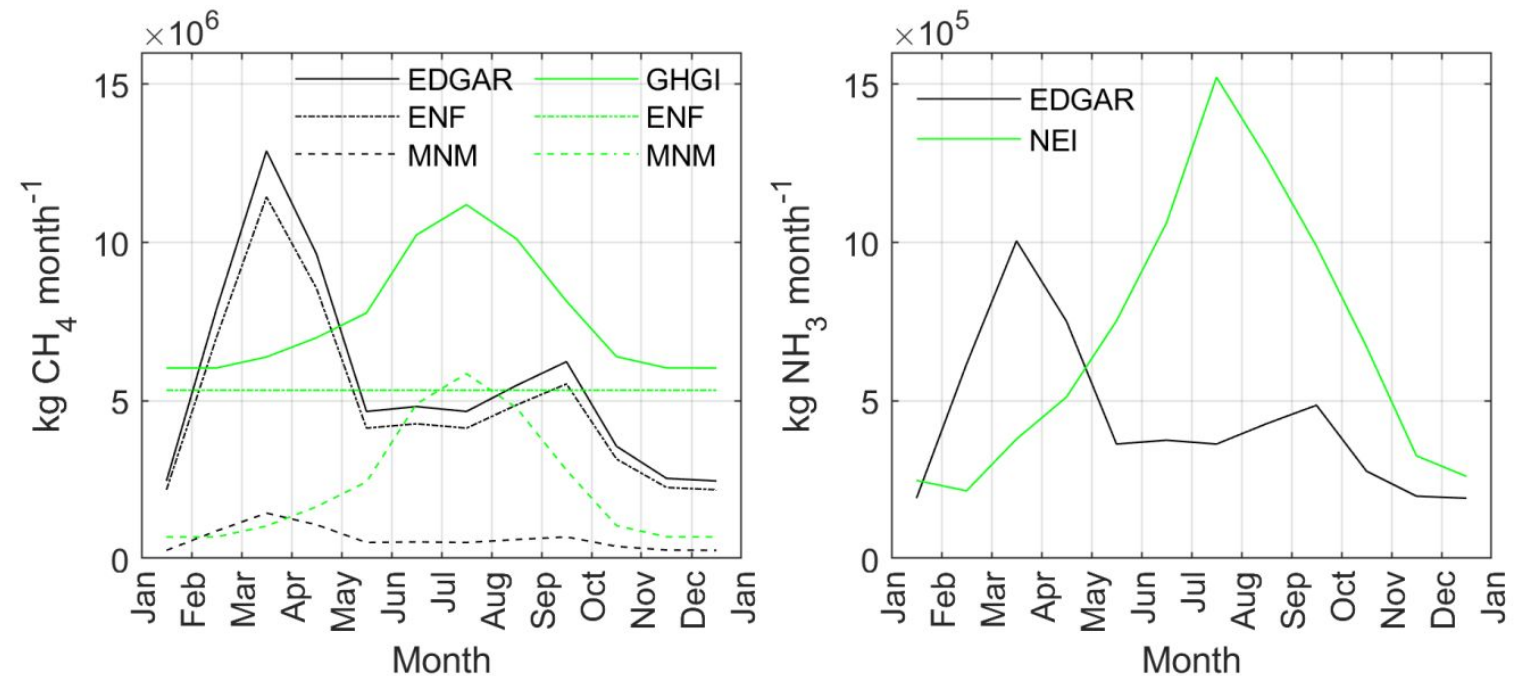

Figure S8. Monthly variation in the emission inventories for (left) $\mathrm{CH}_{4}$ and (right) $\mathrm{NH}_{3}$ integrated over the domain shown in Figure S7. Abbreviations: ENF = enteric fermentation and $\mathrm{MNM}=$ manure management.

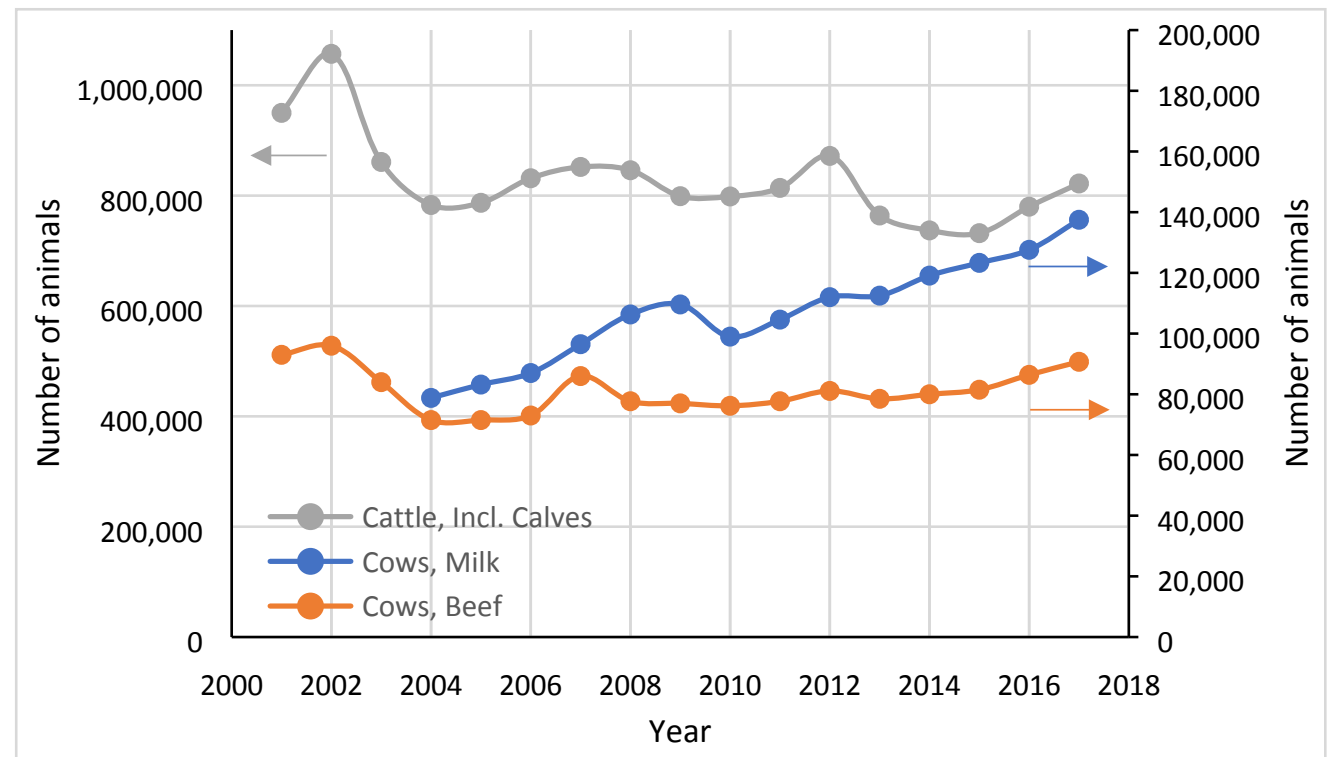

Figure S9. Activity counts for Weld, Larimer, and Morgan Counties (USDA surveys). 


\section{Supplementary references}

Data sources

EDGAR 2018, Global Air Pollutant Emissions EDGAR v4.3.2, http://edgar.jrc.ec.europa.eu/overview.php?v=432 AP

EDGAR 2019, Global Greenhouse Gases Emissions EDGAR v4.3.2, http://edgar.jrc.ec.europa.eu/overview.php? v=432 GHG\&SECURE=123

Maasakkers et. al. 2016, Gridded national inventory of US methane emissions, Environ. Sci. Technol. 50(23): 13123-13133 https://www.epa.gov/ghgemissions/gridded-2012-methane-emissions

USDA 2017, National Agricultural Statistics Service: Quick Stats, https://quickstats.nass.usda.gov/

U.S. EPA 2018, 2014 National Emissions Inventory (NEI) Data, https:/www.epa.gov/airemissions-inventories/2014-national-emissions-inventory-nei-data

U.S. NEI documentation

Asman, W.A.H. 1992, Ammonia emission in Europe: updated emission and emission variations, Report No. 228471008, National Institute of Public Health and Environmental Protection, Bilthoven, The Netherlands

Battye R., W. Battye, C. Overcash, S. Fudge 1994, Development and selection of ammonia emission factors. Final Report prepared by EC/R Incorporated for EPA Atmospheric Research and Exposure Assessment Lab, Research Triangle Park, North Carolina

Bouwman et al. 1997, A global high-resolution emission inventory for ammonia, Global Biogeochem. Cycles 11(4): 561-587

CARB 1999, Estimates of Ammonia Emissions from Beef and Dairy Cattle in California. Review Draft. California Air Resources Board, Sacramento, CA (via USDA 2000 - could not access)

Grelinger 1997, Improved Emission Factors for Cattle Feedlots (via U.S. EPA 2004 - could not access)

Hutchinson, G.L., A.R. Mosier, C.E. Andre 1982, Ammonia and amine emissions from a large cattle feedlot, J. Environ. Qual. 11(2): 288-293

U.S. EPA 2004, National Emission Inventory-Ammonia Emissions from Animal Husbandry Operations: Draft Report

USDA 2000, Air quality research and technology transfer white paper and recommendations for concentrated animal feeding operations, adopted by USDA Agricultural Air Quality Task Force, Washington, D.C. 